\title{
Semen collection in Rusa timorensis under general anaesthesia by using ketamine-xylazine: Clinical study
}

\author{
W.N. Fitri' ${ }^{1}$, H. Wahid², F.F. Jesse ${ }^{1,3}$, S.A. Sarah ${ }^{6,7}$, M.L. Mohd-Azmi ${ }^{4}$, M. Azrolharith ${ }^{5}$, \\ K. Zubaidah ${ }^{8}$, Y. Donny ${ }^{8}$, A. Zulhizri', K.C. Yap $^{10}$ and C.A. Azlan ${ }^{1}$
}

${ }^{1}$ Department of Veterinary Clinical Studies, ${ }^{2}$ Desa Pinggiran Putra, ${ }^{3}$ Institute of Tropical Agriculture and Food Security, ${ }^{4}$ Department of Veterinary Pathology and Microbiology, ${ }^{5}$ Department of Medicine and Surgery of Farm and Exotic Animal, Faculty of Veterinary Medicine, University of Putra Malaysia, Serdang, ${ }^{6}$ Faculty of Applied Sciences, ${ }^{7}$ Malaysia Institute of Transport, University of Teknologi Mara, 40450 Shah Alam, Selangor, ${ }^{8}$ Wildlife Veterinary Section, Ex-Situ Conservation Division, Department of Wildlife and National Park (DWNP), Peninsular, ${ }^{9}$ Department of Veterinary Service, Federal Government Administration Centre, Putrajaya, ${ }^{10}$ Borneo Rhino Alliance, Faculty of Sustainable Agriculture, University of Malaysia Sabah, Jalan UMS, Sandakan, Sabah, Malaysia

\begin{tabular}{l} 
Article information \\
\hline Article history: \\
Received February 02, 2020 \\
Accepted April 07, 2020 \\
Available online August 16, 2020 \\
\hline Keywords: \\
Clinical Study \\
Rusa timorensis \\
Semen \\
General Anaesthesia \\
\hline Correspondence: \\
W.N. Fitri \\
wannorfitri@ upm.edu.my
\end{tabular}

\begin{abstract}
There is a scarcity of information for a reliable and safe protocol for semen collection in $R$. timorensis. The induction of general anesthesia by Ketamine-Xylazine in both intravenous and intramuscular routes provides valuable information for the practicality of the procedure. Five healthy and matured Rusa timorensis stags, aged more than 3 years, weighing an average of $68.5 \pm 2.4 \mathrm{~kg}$ were selected for this experiment. General anaesthesia was conducted by using a combination of Ketamine and Xylazine at the dosage of $2 \mathrm{mg} / \mathrm{kg}$, and $1 \mathrm{mg} / \mathrm{kg}$ respectively in both intramuscular and intravenous routes. The procedure was performed from April to November 2012 resulting in 30 collections. The physiological parameters included were respiratory rate, heart rate and temperature before, during and post-procedure. The onset, recovery and total time are significantly different between IV and IM route at $5.13 \pm 0.88 \mathrm{~min}, 7.47 \pm 1.61 \mathrm{~min}, 18.67 \pm 1.47 \mathrm{~min}$, and $11.67 \pm 1.44 \mathrm{~min}$, $11.73 \pm 1.03 \mathrm{~min}$ and, $29.07 \pm 4.01 \mathrm{~min}$ respectively. Meanwhile, there is no significant difference in the duration time of anesthesia between IV and IM route at 15.27 \pm 3.03 min and $17.40 \pm 3.55$ min respectively. Both routes provide the same success rate and yield the same semen quality, however, the intravenous route is desirable due to fast induction and recovery time. General anaesthesia is integral for the restraining of wild cervidae, intravenous route of drug administration should be considered for semen collection in Rusa deer.
\end{abstract}

DOI: 10.33899/ijvs.2020.126614.1350, (C2021, College of Veterinary Medicine, University of Mosul.

This is an open access article under the CC BY 4.0 license (http://creativecommons.org/licenses/by/4.0/).

\section{Introduction}

The deer industry is rapidly growing in the Asia region. In Malaysia, the deer industry has been developing from the 1980s, rearing deer species such as Damma damma, Axis axis, Cervus nippon, Cervus elaphus and Rusa timorensis (1). Despite years of developing the deer industry, assisted reproductive technology (ART) such as artificial 
insemination in deer is still at its infancy. One of the major factors for the slow development of ART was due to the safety associated risk to the animals (2). The first step of developing ART is in the establishment of a safe and reliable method of semen collection in deer. There have been various studies published on general anaesthesia in other species of deer such as the white-tailed deer, sika deer and Chinese water deer (3-5). The scarcity of the ART in R. timorensis was reflected by the limited studies in semen quality assessment (6). Limited work was done on the topic of semen extension in cryoprotectant of $R$. timorensis $(7,8)$. Therefore, there is a need in the development of the protocol in this area that will encourage more research in deer reproduction and will open more doors for ART application in deer livestock. General anaesthesia in deer especially in $R$. timorensis are rarely studied yet is important for various veterinary procedures which include the semen collection. Semen collection is a procedure that is relatively safe and quick to perform however is often perceived as perilous and unnecessary to the animal (9).

Semen collection using electroejaculation under general anaesthesia appears to be the only viable option in the untrained stag. Recently, semen collection using electroejaculation in the anaesthetized animal has been performed in deer and other wildlife to study the semen motility (10-13). Therefore, electroejaculation using general anaesthesia method is the most appropriate and efficient method currently favouring the welfare of the animal (14).

This study was performed to investigate a reliable and safe protocol for semen collection by electroejaculator in Rusa timorensis under general anaesthesia of ketaminexylazine which was administered intravenous and intramuscular routes.

\section{Materials and Methods}

\section{Animals and management}

Five healthy and matured $R$. timorensis stags, aged more than 3 years, weighing an average of $68.5 \pm 2.4 \mathrm{~kg}$ was selected for this experiment. The stags were weighed each time before general anaesthesia and semen collection procedure using a digital weighing machine installed in the crush. The deer were kept in a cyclone-fenced paddock managed as a herd together with hinds in Taman Pertanian University, Unit Ruminan Kecil, University Putra Malaysia. The stags were vaccinated against foot and mouth disease (FMD) and dewormed regularly following the farm herd health program. The deer were allowed to graze paddock with signal grass, Brachiaria decumbens and additional supplement of cut and carry Napier grass and palm kernel cake was provided to the deer. Water was provided at ad libitum. This research was conducted under the monitoring and approval of Animal Care and Use Ethics Committee, Universiti Putra Malaysia (Reference Number: FPV/PU/B901).

\section{General anaesthesia}

The deer were herded from the paddock into the dark house as the deer are calmer in the dark house, which allowing for physical restraint in small-sized area (15). The head of the deer was controlled by farmer, while other person held the deer shoulder while exerting downward pressure to prevent the deer from jumping (16). General anaesthesia was conducted using a combination of Ketamine and Xylazine at the dosage of $2 \mathrm{mg} / \mathrm{kg}$ and, $1 \mathrm{mg} / \mathrm{kg}$ respectively (17). Ketamine that was used in this study is under the trade name of Narketan ${ }^{\circledR}$ (Vetoquinol UK) while Xylazine was Rompun ${ }^{\circledR}$ (Paramount Rx) where both anaesthetic drugs was at $10 \%$. Two most common routes of general anaesthesia were chosen for this study are the intravenous route via the jugular vein (18) and intramuscular route via deep gluteus maximus muscle (19). The administration procedure of intravenous and intramuscular routes for both anaesthetic drugs was performed on each individual for twice in a month for a period of 8 months (April to November 2012). The total attempts of general anaesthesia were 15 in each route (total of 30 attempts). The dosage for yohimbine given to the animal intravenously to revive the animal was at $0.1 \mathrm{mg} / \mathrm{kg}$ (20). The time of onset for the drug to take action was recorded after drug administration until the animal went to sternal recumbency position. Time taken for the duration of anaesthesia was from recumbence until ejaculation. Recovery time was the time taken after Yohimbine administration until the animal was on sternal recumbency. The animal was placed in right lateral recumbency during the semen collection procedure.

\section{Physiological parameters monitoring}

Monitoring of vital signs are respiratory rate, heart rate and temperature were taken pre, peri and post anaesthesia procedure. Pre anaesthesia period is the parameter taken before the administration of drugs and it is from the period of a physical restraint. The data were pooled together for the intramuscular and intravenous route. Peri anaesthesia period is the parameter taken after the delivery of drugs either via the intramuscular or intravenous route. Post anaesthesia period is the time taken after the injection of a reversal agent, Yohimbine intravenously to revive the animal. During the anaesthesia procedure, three stages of respiratory and heart rates were recorded; early, middle and towards the end of the procedure at five minutes interval. The quality of anaesthesia induction and recovery were subjectively evaluated based on the established method in white-tailed deer from a score of 1 to $5 ; 1=$ excellent, $2=$ good, $3=$ fair, $4=$ =poor, and $5=$ unacceptable (21). The stage and plane of anaesthesia in deer were assessed according to a standard in deer (22) and maintained at deep plane during the electroejaculation procedure. Time of onset was taken after drug administration until the animal went down to sternal 
recumbency. Time taken for the duration of anaesthesia was from recumbency until ejaculation. Recovery time was the time taken after yohimbine administration until the animal was on sternal recumbency. Supplements were given intramuscularly, Vitavet ${ }^{\circledR}$ (Nova) containing vitamin $\mathrm{A}, \mathrm{B}, \mathrm{C}, \mathrm{D}$ and $\mathrm{E}$ and, Catosal ${ }^{\circledR}$ (Bayer) consisting of vitamin B12,10ml on each side of the rump as recommended on the label.

\section{Semen collection}

Semen collection was performed using electroejaculation (P-T Electronics, Boring, USA). Before electroejaculator probe was inserted, faeces were evacuated from the rectum. The electroejaculator probe was lubricated with KY-Jelly. A generous application of lubricant and gentle probe insertion was necessary due to the fold and sensitive layer of rectal mucosa in deer to prevent bleeding. The probe was inserted, retracted and repositioned preventing rectal mucosa fold trauma by gentle advancement of the probe. Probe insertion was gauged from a low voltage stimulation and slow increase of the voltage. Good response from the electric stimulation was observed by the hind limbs flexion. Semen was collected in the graduated tube and quantify using a micropipette, while concentration of sperm was achieved using semen counting chamber. Semen characteristics were compared to identify the difference between the two routes of drug administration. The best route of drug administration was chosen for semen motility. The choice of semen extender used was Andromed $®$ based the best performing extender for $R$. timorensis (23).

Semen was collected twice monthly from each individual from months of April to November. Success in semen collection was noted in each collection session, the success rate was recorded and reported as a percentage. Semen collection procedure was conducted from a modified protocol in wildlife species (10). The electrical stimulations were at a 3-sec-on and 1-sec-off rhythm, with 3 repetitions before subsequent volt increment and 1-minute rest between each series. Electrical stimulations were delivered into three parts; from $1 \mathrm{~V}$ to $6 \mathrm{~V}$, restarting back from $1 \mathrm{~V}$ to $12 \mathrm{~V}$, and finally from $1 \mathrm{~V}$ to $18 \mathrm{~V}$. During electrical stimulation, muscle contraction was observed which also suggest appropriate contact of the probe with rectal mucosa and stimulation to the sex glands.

\section{Statistical Analysis}

Data were analyzed using IBM SPSS Statistics ver. 20. Data were examined using one-way analysis of variance (ANOVA) to determine differences between the mean time of intravenous and intramuscular routes. The means were considered significant at the level of $P<0.05$. One-way analysis of variance was also used in comparing intramuscular and intravenous parameters as well as comparing the temperature, pulse and respiratory parameters of pre (control), peri and post anaesthesia. Spearman rho was used to indicate correlations between parameters and the strength of correlation was reported based on general statistics rule: 0.90 to 1 very high, 0.70 to 0.90 high, 0.50 to 0.70 moderate, 0.30 to 0.50 low and 0.0 to 0.30 negligible correlation (24).

\section{Results}

The onset, duration, recovery and total time of anaesthesia procedure was recorded. There was a significant difference between onset, recovery and total time in intravenous and intramuscular routes. The onset, recovery and total time of anaesthesia for the intravenous route were $5.13 \pm 0.88 \mathrm{~min}, 7.47 \pm 1.61 \mathrm{~min}$ and $18.67 \pm 1.47 \mathrm{~min}$ while intramuscular route were $11.67 \pm 1.44 \mathrm{~min}, 11.73 \pm 1.03 \mathrm{~min}$ and $29.07 \pm 4.01 \mathrm{~min}$ respectively. In contrast, there was no significant difference in the duration time of anesthesia between intravenous and intramuscular routes which were $15.27 \pm 3.03 \mathrm{~min}$ and $17.40 \pm 3.55 \mathrm{~min}$. The results of onset, duration, recovery, total time and success of semen collection in different routes of drugs administered in $R$. timorensis are summarized in Table.

There was no significant difference between the successes of semen collection compared between intravenous or intramuscular routes at $93.3 \%$ and $79 \%$. There was a significantly high positive correlation between the duration time and total time in both intravenous and intramuscular routes with a Spearman's rho value of $(\rho)=$ 0.834 and $(\rho)=0.861$ respectively. These correlations suggest that the duration time to achieve ejaculation is the main factor that contributes to the total time of anaesthesia in both routes.

There was no significant difference between the successes of semen collection compared between intravenous or intramuscular routes at $93.3 \%$ and $79 \%$. There was a significantly high positive correlation between the duration time and total time in both intravenous and intramuscular routes with a Spearman's rho value of $(\rho)=$ 0.834 and $(\rho)=0.861$ respectively. These correlations suggest that the duration time to achieve ejaculation is the main factor which contributes to the total time of anaesthesia in both routes.

The descriptive statistics of anaesthetic monitoring between intravenous and intramuscular were recorded in Table 2. The parameters taken were heart rate, respiratory rate and temperature prior (pre), during (peri) and after (post) anaesthesia. The parameter for heart rate, respiratory rate and temperature in pre anaesthesia period was $115.5 \pm 2.0$ beats/min, $78.8 \pm 1.7 \mathrm{bpm}$ and $38.1 \pm 0.0{ }^{\circ} \mathrm{C}$. The heart rate, respiratory rate, temperature, stage, plane and quality during (peri) anaesthesia in intravenous and intramuscular were $79.1 \pm 1.41$ beats $/ \mathrm{min}, 61.9 \pm 1.6 \mathrm{bpm}, 38.0 \pm 0.0^{\circ} \mathrm{C}, 2.9 \pm$ $0.0,1.8 \pm 0.1,1.0 \pm 0.1$ and $52.0 \pm 6.1$ beats $/ \mathrm{min}, 35.3 \pm 2.9$ bpm, $39.3 \pm 0.3^{\circ} \mathrm{C}, 3.0 \pm 0.0,3.3 \pm 0.3$ and $3.0 \pm 0.0$ respectively. The heart rate was lower and the mean was 
significantly different during and post anaesthesia in intramuscular compared to the intravenous route which was $52.0 \pm 6.1$ beats $/ \mathrm{min}$ peri anesthesia then become $65.0 \pm 5.0$ beats/min post anesthesia and, $79.1 \pm 1.4$ beats/min peri anesthesia become $119.8 \pm 2.0$ beats/min post anesthesia respectively. The respiratory rate was also lower in intramuscular compared to intravenous routes which were, $35.3 \pm 2.9 \mathrm{bpm}$ peri anesthesia then become $36.7 \pm 3.3 \mathrm{bpm}$ post anesthesia and, $61.9 \pm 1.6 \mathrm{bpm}$ peri anesthesia then become $88.3 \pm 2.1 \mathrm{bpm}$ post anesthesia. The temperature was consistently higher and the mean was significantly different between intramuscular and intravenous routes prior, during and post anaesthesia at $38.1 \pm 0.0^{\circ} \mathrm{C}, 39.3 \pm 0.3^{\circ} \mathrm{C}, 39.3 \pm$ $0.3^{\circ} \mathrm{C}$ and $38.1 \pm 0.0^{\circ} \mathrm{C}, 38.0 \pm 0.0^{\circ} \mathrm{C}$ and, $38.2 \pm 0.1^{\circ} \mathrm{C}$. The quality of anaesthesia was better and significantly different between intravenous and intramuscular routes during and post anaesthesia $1.0 \pm 0.1,1.0 \pm 0.0$ and $3.0 \pm 0.0,2.3 \pm 0.3$. During anaesthesia, the plane of anaesthesia plunged to a deeper plane of anaesthesia in intramuscular route at plane $3.3 \pm 0.3$ compare to $1.8 \pm 0.1$ in intravenous route.

Table 1: Onset, duration and recovery time in minutes (mean \pm SEM) in general anaesthesia via intravenous and intramuscular routes in R. timorensis

\begin{tabular}{lcccc}
\hline \multirow{2}{*}{ Parameters } & \multicolumn{2}{c}{ Intravenous } & \multicolumn{2}{c}{ Intramuscular } \\
\cline { 2 - 5 } & Mean & Range & Mean & Range \\
\hline Onset Time (min) & $5.13 \pm 0.88^{\mathrm{a}}$ & $1-15$ & $11.67 \pm 1.44^{\mathrm{b}}$ & $7-25$ \\
Duration Time (min) & $15.27 \pm 3.03^{\text {***}}$ & $2-54$ & $17.40 \pm 3.55^{\mathrm{a}^{* * *}}$ & $6-51$ \\
Recovery Time (min) & $7.47 \pm 1.61^{\mathrm{a}}$ & $2-25$ & $11.73 \pm 1.03^{\mathrm{b}}$ & $4-22$ \\
Total Time & $18.67 \pm 1.47^{\mathrm{a}^{* *}}$ & $12-32$ & $29.07 \pm 4.01^{\mathrm{b}^{* *}}$ & $13-62$ \\
Success of semen collection (\%) & 93.3 & - & 79 & - \\
\hline
\end{tabular}

Onset time - time taken from drug administration to recumbency. Duration time - taken from probe insertion until ejaculation. Recovery time - time taken from lateral recumbency to sternal recumbency post I/V Yohimbine injection. Total time - time taken from onset towards the entire duration and recovery from anaesthesia. ${ }^{a b}$ Means values in the same rows with different superscripts are significantly different at $P<0.05$. **statistically significant correlation within column $(P<0.01)$. I/V: intravenous. I/M: intramuscular.

Table 1: The descriptive statistics between two routes of anaesthesia in R. timorensis

\begin{tabular}{llcccc}
\hline \multirow{2}{*}{ Time } & \multirow{2}{*}{ Parameter } & \multicolumn{2}{c}{ Intravenous } & \multicolumn{2}{c}{ Intramuscular } \\
\cline { 2 - 5 } Pre Anesthesia & Mean \pm SEM & Range & Mean \pm SEM & Range \\
& $\mathrm{H} / \mathrm{R}(\mathrm{beats} / \mathrm{min})$ & $115.5 \pm 2.0^{\mathrm{c}}$ & $76.0-145.0$ & $115.5 \pm 2.0^{\mathrm{c}}$ & $76.0-145.0$ \\
& $\mathrm{R} / \mathrm{R}(\mathrm{bpm})$ & $78.8 \pm 1.7^{\mathrm{c}}$ & $32.0-112.0$ & $78.8 \pm 1.7^{\mathrm{c}}$ & $32.0-112.0$ \\
& Temp $\left({ }^{\circ} \mathrm{C}\right)$ & $38.1 \pm 0.0^{\mathrm{c}}$ & $37.1-39.1$ & $38.1 \pm 0.0^{\mathrm{c}}$ & $37.1-39.1$ \\
\hline \multirow{5}{*}{ Peri Anesthesia } & $79.1 \pm 1.4^{\mathrm{a}, \mathrm{d}}$ & $32.0-126.0$ & $52.0 \pm 6.1^{\mathrm{b}, \mathrm{d}}$ & $40.0-60.0$ \\
& $\mathrm{H} / \mathrm{R}(\mathrm{beats} / \mathrm{min})$ & $61.9 \pm 1.6^{\mathrm{a}, \mathrm{d}}$ & $22.0-110.0$ & $35.3 \pm 2.9^{\mathrm{a}, \mathrm{d}}$ & $30.0-40.0$ \\
& $\mathrm{R} / \mathrm{R}(\mathrm{bpm})$ & $38.0 \pm 0.0^{\mathrm{a}, \mathrm{c}}$ & $36.0-39.0$ & $39.3 \pm 0.3^{\mathrm{b}, \mathrm{c}}$ & $39.0-40.0$ \\
& Temp $\left({ }^{\circ} \mathrm{C}\right)$ & $2.9 \pm 0.0^{\mathrm{a}}$ & $2.0-3.0$ & $3.0 \pm 0.0^{\mathrm{a}}$ & 3.0 \\
& Stage $(\mathrm{I}$ to III) & $1.8 \pm 0.1^{\mathrm{a}}$ & $1.0-4.0$ & $3.3 \pm 0.3^{\mathrm{b}}$ & $3.0-4.0$ \\
& Plane $(1$ to 4$)$ & $1.0 \pm 0.1^{\mathrm{a}}$ & $1.0-3.0$ & $3.0 \pm 0.0^{\mathrm{b}}$ & 3.0 \\
\hline \multirow{5}{*}{ Post Anesthesia } & Quality (1-5) & $119.8 \pm 2.0^{\mathrm{a}, \mathrm{c}}$ & $72.0-144.0$ & $65.0 \pm 5.0^{\mathrm{b}, \mathrm{c}}$ & $60.0-80.0$ \\
& $\mathrm{H} / \mathrm{R}(\mathrm{beats} / \mathrm{min})$ & $88.3 \pm 2.1^{\mathrm{a}, \mathrm{c}}$ & $42.0-130.0$ & $36.7 \pm 3.3^{\mathrm{b}, \mathrm{c}}$ & $30.0-40.0$ \\
& R/R (bpm) & $38.2 \pm 0.1^{\mathrm{a}, \mathrm{c}}$ & $37.0-39.1$ & $39.3 \pm 0.3^{\mathrm{b}, \mathrm{c}}$ & $39.0-40.0$ \\
& Temp $\left({ }^{\circ} \mathrm{C}\right)$ & $1.0 \pm 0.0^{\mathrm{a}}$ & 1.0 & $2.3 \pm 0.3^{\mathrm{b}, \mathrm{c}}$ & $2.0-3.0$ \\
\hline
\end{tabular}

bpm=breaths per minute, $\mathrm{H} / \mathrm{R}=$ heart rate, $\mathrm{R} / \mathrm{R}=$ respiratory rate. Quality - Quality of anaesthesia was scored from 1 (excellent) to 5 (poor). Stage - Stage of anaesthesia was scored from Stage I (excitement) to Stage III (surgical anaesthesia). Plane - Plane of anaesthesia was scored from Plane 1 (light) to Plane 4 (excessive deep). ${ }^{\text {ab }}$ Means values in the same rows with different superscripts are significantly different. ${ }^{\text {cd }}$ Means values in the same column with different superscripts are significantly different.

The overall pattern of time for both onset and recovery time is faster in intravenous compared to the intramuscular routes of drug administration. The onset and recovery time are both different between intramuscular and intravenous route. The mean onset for intramuscular and intravenous routes are significantly different at $11.67 \pm 1.44 \mathrm{~min}$ and 5.13 $\pm 0.88 \mathrm{~min}$ respectively. The time of onset is lower in intravenous compared to intramuscular route although on the second trial the standard error of mean overlapped. The consistent low time of onset suggests the high consistency and reliability of ketamine-xylazine administered intramuscularly. The standard error of mean is low in all 
batch except the fourth in the intramuscular route which supports the choice of intravenous as the better route of drug administration in $R$. timorensis due to low variability in time of onset. The time of onset in the intravenous route in each batch is lower than the mean of intramuscular on all occasions.

The mean recovery time for drug administration via intramuscular and intravenous route are significantly different at $11.73 \pm 1.03 \mathrm{~min}$ and $7.47 \pm 1.61 \mathrm{~min}$ respectively. The mean recovery time is shorter in intravenous compared to the intramuscular route. The variability in recovery time intravenous was higher in compared to the intramuscular route. However, the recovery time in the intravenous route is still shorter than the mean recovery time of the intramuscular route except for the second and sixth trial batch. When compared between batches of recovery time, only the sixth batch of the intravenous route has the mean recovery time higher than the intramuscular route. In addition to that, comparing the preanaesthesia, peri and post anaesthesia temperature, pulse and respiratory rate revealed that there was a significant difference between pre and peri anaesthesia pulse and respiratory while temperature has no significant difference. There was no significant difference between pre and post anaesthesia pulse and respiratory rate as well.

The semen parameters collected between the two routes of drug administration were tabulated in Error! Reference source not found. The semen parameters for intravenous route are general motility, wave pattern, semen concentration, semen volume and total semen concentration at $78.33 \pm 2.71 \%, 3.50 \pm 0.15,1530.36 \pm 247.61 \times 10^{6} / \mathrm{ml}$, $1.16 \pm 0.19 \mathrm{ml}$, and $1535.69 \pm 400.86 \times 10^{6} / \mathrm{ml}$ respectively. Meanwhile the semen values for intramuscular route that was non-statistically significant different are $79.55 \pm 4.69 \%, 3.46$ $\pm 0.16,1191.97 \pm 360.25 \times 10^{6} / \mathrm{ml}, 1.71 \pm 0.65 \mathrm{ml}$ and $1765.59 \pm 404.58 \times 10^{6} / \mathrm{ml}$.

Table 2: Semen parameters collected between the two routes of drug administration

\begin{tabular}{lcccc}
\hline \multirow{2}{*}{ Parameter } & \multicolumn{2}{c}{ Intravenous } & \multicolumn{2}{c}{ Intramuscular } \\
\cline { 2 - 5 } & Mean \pm SEM & Range & Mean \pm SEM & Range \\
\hline General motility $(\%)$ & $78.33 \pm 2.71^{\mathrm{a}}$ & $65.00-90.00$ & $79.55 \pm 4.69^{\mathrm{a}}$ & $50.00-95.00$ \\
Wave Pattern $(1-5)$ & $3.50 \pm 0.15^{\mathrm{a}}$ & $3.00-4.00$ & $3.46 \pm 0.16^{\mathrm{a}}$ & $3.00-4.00$ \\
Semen Concentration $\left(\times 10^{6} / \mathrm{ml}\right)$ & $1530.36 \pm 247.61^{\mathrm{a}}$ & $37.50-3560.00$ & $1191.97 \pm 360.25^{\mathrm{a}}$ & $37.50-4075.00$ \\
Semen Volume $(\mathrm{ml})$ & $1.16 \pm 0.19^{\mathrm{a}}$ & $0.30-2.30$ & $1.71 \pm 0.65^{\mathrm{a}}$ & $0.80-3.00$ \\
Total Semen Concentration $\left(\times 10^{6} / \mathrm{ml}\right)$ & $1535.69 \pm 400.86^{\mathrm{a}}$ & $78.75-3854.40$ & $1765.59 \pm 404.58^{\mathrm{a}}$ & $165.00-4075.00$ \\
\hline
\end{tabular}

${ }^{a}$ Mean value in the same.

\section{Discussion}

General anaesthesia study has been performed successfully in various species of deer (25), and is an eminent in deer semen collection procedure. However, the study of general anaesthesia in relation to semen collection remains limited (26), though it is the only method of semen collection in untrained animals. Moreover, the recorded anaesthesia protocol in R. timorensis remains scarce (8). The knowledge gained from other species of deer that can be applied to the whole deer family, especially these species with lack of study. This is however inaccurate since the species-specific reaction to the drug may exist and extrapolation between species can be inappropriate as there are even differences across individuals of the same species (27).

It was important to note that there was no mortality due to anaesthesia in this study since deer are known to be prone to hyperthermia, capture myopathy and trauma (28-30). Thus, there is a need to have a close monitor of the body temperature of the animal. Besides that, a cooling mechanism such as using a wet towel or water must be considered in the procedure. In a study, the use of anaesthesia was found to reduce the risk of mortality in capture animal which highlights the importance of anaesthesia in deer (20). Different from domestic animals, semen collection procedure requires the use of anaesthesia (31). Training stags for artificial vagina were no longer practiced despite being the early method of semen collection in deer in the 1980s as the procedure was proven to be risky to the handler (32). A degree of training is also required for the stag to be used with artificial vagina which prompts further time and effort to train the animal as opposed to no training requirement in electroejaculation procedure (33). An anaesthetic protocol using a combination of Ketamine- Xylazine and reversal with Yohimbine is safe and practical to use in R. timorensis for the semen collection procedure. The same combination of Ketamine-Xylazine drugs and Yohimbine reversal was also recommended in spotted deer and was successfully applied for electroejaculation purpose (17).

The total time taken for a successful semen collection procedure varied between intramuscular and intravenous routes. The time to obtain semen through electroejaculation is not a primary factor that contributes to the total time of the procedure as there is no significant difference between either two routes of drug administration. The result from our study which suggests that the time of anaesthesia between two routes of drug administration not having an effect on the total period of anaesthesia is consistent with a study in human with no difference in the time of discharge between routes of drug administration (34). Thus, the time difference was due to the 
time of onset and recovery time as the correlation suggests. The time of onset for Ketamine- Xylazine is faster in the intravenous route than the intramuscular route. The pharmacodynamic of Ketamine distribution was found to be faster in the intravenous route compared to intramuscular contributing to the rapid onset of anaesthesia (35). The result of this study is aligned with a study suggesting Ketamine used intravenously in deer having rapid absorption (36). Ketamine has low bioavailability and reaches a slower time of effect in intramuscular posing to higher loading dose for the drug to take effect $(37,38)$. Usage of Xylazine was reported to improve sedation, muscle relaxation, induction and recovery in white-tailed deer (21). The onset time of Ketamine- Xylazine was slower in intramuscular as opposed to intravenous due to the different pharmacodynamics in the two routes of drug administration.

The use of alpha $2_{2}$-antagonists such as Yohimbine provides better recovery to the alpha 2 -agonist drug like Xylazine. Yohimbine was reported to provide smoother recovery and shorter arousal post anaesthesia (21). Due to slower absorption of Ketamine- Xylazine in intramuscular route and residual drug effects, prolonged recovery is expected (39). Subsequently, the recovery with Yohimbine was slower in intramuscular route with lower heart rate post anaesthesia at $65.0 \pm 5.0$ beats/min as opposed to intravenous $119.8 \pm 2.0$ beats $/ \mathrm{min}$. As a result, the satisfactory of recovery post anaesthesia in intramuscular contributes to the lower quality of anaesthesia at $2.3 \pm 0.3$ as opposed to $1.0 \pm$ 0.0 in intravenous route. In conclusion, the total time taken for semen collection was influenced by the onset of Ketamine- Xylazine and the recovery time using Yohimbine as the reversal.

This study highlights the success of semen collection by general anaesthesia via the intramuscular and intravenous route. There was no significant difference in the success of semen collection between both routes. Induction via intravenous is only practical in farm settings with the wellequipped dark house while intramuscular is commonly used in field settings. Establishment of venous access, risks related to venous access and maintenance of venous access are one of the few challenges in the field (40). However, there is no significant difference in the success of semen collection in $R$. timorensis in farm settings. Therefore, in either routes of drug administration, semen collection procedure should be considered. General anaesthesia using a remote delivery system via intramuscular is more common in wildlife, partially sedated or fully induced and can be maintained safely (20). The use of drugs to tranquillize animals for management procedure is more preferable than physical restraint alone and will improve the welfare of animal by controlling the effect it has on stress (28).

The time of onset and recovery is significantly faster in intravenous compared to intramuscular. The breakdown of the results, however, revealed sporadic spike and reduction in the time taken for onset and recovery regardless of the route of drugs administration. The differences in time were explained by a study of Ketamine pharmacokinetic in the absorption and distribution in which intravenous route was faster than the intramuscular route (41). Moreover, Xylazine residue and elimination are more rapid in the intravenous route compared to the intramuscular route (42). Besides the pharmacokinetics, there are many factors that should be taken into account with the induction of Ketamine and Xylazine such as physiological, age and individual differences which could affect the drug effect (37). In deer, there might be different tolerance of individuals towards stress and handling. This trait was displayed by a recent study in $R$. timorensis which look into the different stress effect between different individuals which suggest different tolerance level towards handling and stress (43). Despite the fluctuation in data, this study suggests intravenous as the best rote of anaesthesia due to the better rate of onset and recovery time in $R$. timorensis.

More importantly, the difference between onset and recovery time has an impact on the deer industry. The onset and recovery time in this study is shorter in the intravenous route compared to the intramuscular route. In fact, the impact of a shorter period of time in procedure due to the different drug administration routes may be a key factor in the progress of assisted reproductive technology in deer. One of the important challenges of artificial insemination in domestic animals is in the cost incurred for the procedure (44). The case is especially true in case of cost for drugs administration which may take long recovery time warranting extended monitoring time (18). Reducing time in induction and recovery will allow for the reduction in cost incurred for semen collection by reducing operational time and manpower involved in the procedure and anaesthesia monitoring. Thus, reducing the time taken for semen collection procedure indirectly will contribute to the growth of artificial insemination in the deer industry. The benefit of the intravenous route of drug administration highlighted in this study will promote more artificial insemination procedures in the future.

Both routes of drug administration have notable cardiovascular depression as an effect of Ketamine Xylazine anesthesia. However, the heart rate was lower in intramuscular compared to intravenous since the readings were taken after premedication with Ketamine- Xylazine. The lower heart rate suggests a calming effect and better stress management for the animal (28). Normal heart rate in deer is 60 beats/min (45) while the normal respiratory rate of deer is $16-20$ breaths $/ \mathrm{min}$ (22). The heart rate pre anaesthesia elevated as high as 126 beats/min due to restraint in this study then stabilized after the onset of anaesthesia. However, the recovery of the animal was delayed in the intramuscular route due to the slow distribution of drug intramuscularly and the deeper plane of anaesthesia. Hence, the advantage of the intravenous route of ketamine delivery was described as the ability to titrate the drug to effect and maintaining the 
appropriate depth of anaesthesia (34). Consequently, a deeper plane of anaesthesia will require closer monitoring of anaesthesia and a higher risk of a failed procedure due to the emergency revival of the animal.

The significant differences inpulse and respiratory rate between pre and peri in different routes of anaesthesia suggest that Ketamine-Xylazine provides distinct physiological parameter and profound cardiovascular depression in $R$. timorensis. The different pulse and respiratory in both routes also suggests that Ketamine and Xylazine were adequate in producing physiological sedation in $R$. timorensis. This is in line with the vital parameter from other deer and small ruminant during anaesthesia $(46,47)$. However, the use of $\alpha_{2}$ adrenergic receptor antagonists such as Yohimbine is still warranted as a reversal for a smoother recovery (19). Meanwhile, there is no difference between pre and post anaesthesia which supports the physiological recovery of the animal to the former state before anaesthesia.

Semen parameters in $R$. timorensis have no significant difference between the different routes of drug administration. The results suggest that the methods to achieved general anaesthesia has no effect on the success and quality of semen parameters. Therefore, suggested that the data can for semen characteristics be used as a reference value and has a consistency comparable to a recent study in $R$. timorensis (23). The procedure of general anaesthesia for semen collection has been proven useful in domestic animals and has yielded good-quality semen (48).

\section{Conclusion}

General anaesthesia is crucial for the welfare of the animal during semen collection in wildlife and deer. The protocol is also an integral foundation for the development of ART in deer. Intravenous and intramuscular routes of Ketamine $(2 \mathrm{mg} / \mathrm{kg})$ and Xylazine $(1 \mathrm{mg} / \mathrm{kg})$ administration is safe and reliable in providing general anaesthesia for the purpose of semen collection in R. timorensis. However, the intravenous route is the best choice of general anaesthesia since it offers quick induction and recovery. Monitoring animal under general anaesthesia is vital for the safety and success of a protocol, information from this manuscript is filling in the data for a guideline to monitor anaesthesia in deer. The semen parameters using a combination of Ketamine - Xylazine offers satisfactory results to semen motility. The success and semen parameters of semen collection via induction of intravenous and intramuscular are the same, therefore semen collection using electroejaculator should be considered as part of a common standard of breeding soundness evaluation in deer and other wildlife.

\section{Acknowledgements}

The authors wish to thank the staff of the University Putra Malaysia (UPM) Deer Breeding Unit, TPU, Mr Zulfakarudin
Zamri, Mr Azrul Hisham, Mr Jeeva a/l Krishnan and Ms Aznida Che Alli for their help with animal restraint during semen collection. We thank $\mathrm{Mr}$ Yap Keng Chee, Mr Ganesamurthi, Mr Fahmi Mahsuri, Mr Aizad and Mr Faizal for their assistance. Not forgetting Dr Zahidah Izzati Zeid for her technical consultation. This research was supported by University Putra Malaysia Grant 2016, GPIPS/2016/9483300 and Fundamental Research Grant Scheme (FRGS), 07-01-16-1825FR.

\section{Conflict of interest}

The authors have no competing interest with other parties for this research.

\section{References}

1. Department of veterinary services. Malaysian livestock breeding policy; 2013. 16-7p.

2. Morrow CJ, Penfold LM, Wolfe BA. Artificial insemination in deer and non-domestic bovids. Theriogenol. 2009;71(1):149-65. Doi: 10.1016/j.theriogenology.2008.09.001.

3. Bouts T, Taylor P, Berry K, Routh A, Gasthuys F. Evaluation of medetomidine-ketamine and dexmedetomidine-ketamine in Chinese water deer (Hydropotes inermis). Vet Anaesth Analg. 2011;38(2):10612. Doi: 10.1111/j.1467-2995.2010.00591.x.

4. Delgiudice G, Sampson B, Kuehn D, Powell C, Fieberg J. Understanding margins of safe capture, chemical immobilization, and handling of free-ranging white-tailed deer. Wild Soc Bull. 2005;33(2):677-87. Doi: 10.2193/00917648(2005)33[677:UMOSCC]2.0.CO;2.

5. Scala C, Locatelli Y, Simon N. Population pharmacokinetics of methadone hydrochloride after a single intramuscular administration in adult Japanese sika deer (Cervus nippon nippon). Vet Anaesth Analg. 2015;42:165-72. Doi: 10.1111/vaa.12186.

6. Mahre M, Wahid H, Rosnina Y, Jesse F, Azlan C, Khumran A. Sperm attributes and morphology on Rusa timorensis: Light and scanning electron microscopy. Anim Reprod Sci. 2014;148(3-4):245-50. Doi: 10.1016/j.anireprosci.2014.06.006.

7. Mesang-Nalley WM, Handarini R, Arifiantini R, Yusuf TL, Purwantara B, Semiadi G. Estrus synchronization and artificial insemination in timor deer. J Vet. 2011;12(4):269-74. [available here]

8. Davide M, Eduardo Z, Sudsukh A, Michele LG, Thongtip N. Post Thawing effects of three cryopreservation diluents on rusa deer (Rusa timorensis) Spermatozoa. Reprod Domest Anim. 2018;0-1. Doi: 10.1111/rda.13380.

9. Holt WV, Lloyd RE. Artificial insemination for the propagation of candes: The reality! Theriogenol. 2009;71(1):228-35. Doi: 10.1016/j.theriogenology.2008.09.003.

10. Wahid H, Ming Y, Zainal ZZ. Evaluation of semen collected by electroejaculation from captive lesser Malay chevrotain (Tragulus javanicus). Am Assoc Zoo Vet. 2000;31(2):164-7. Doi: 10.1638/10427260(2000)031[0164:EOSCBE]2.0.CO;2.

11. Rittem S, Thongthainun D, Tipkantha W, Siriaroonrat B, Thongtip N. Effects of semen extender on motility and movement patterns of frozenthawed eld's deer (Cervus eldii) spermatozoa. Thai J Vet Med. 2012;42(4):527-32. [available here]

12. Fitri WN, Haron A, Rosnina Y, Jesse FFA, Aimi Sarah ZA, Mohd. Azmi ML. Determination of breeding seasonality in rusa deer (Rusa timorensis) stags via serum testosterone profiling. Am J Anim Vet Sci. 2017;12(1):45-52. Doi: 10.3844/ajavsp.2017.45.52.

13. Fitri W-N, Wahid H, Rinalfi PT, Rosnina Y, Raj D, Donny Y. Digital massage for semen collection, evaluation and extension in Malaysian 
estuarine crocodile (Crocodylus porosus). Aquacult. 2018;483. Doi: 10.1016/j.aquaculture.2017.10.026.

14. Palmer CW. Welfare aspects of theriogenology: Investigating alternatives to electroejaculation of bulls. Anim Welfare. 2005;64:46979. Doi: $10.1016 / j$.theriogenology.2005.05.032.

15. Mattiello S. Welfare issues of modern deer farming. Ital J Anim Sci. 2010;8(1):205-17. Doi: 10.4081/ijas.2009.s1.205.

16. Camargo CMS, Duarte JMB, Fagliari JJ, Santana AM, Simplício KMMG, Santana AE. Effect of sex and seasons of the year on hematologic and serum biochemical variables of captive brown brocket deer (Mazama gouazoubira). Pesqui Vet Bras. 2013;33(11):1364-70. Doi: $10.1590 /$ S0100-736X2013001100013.

17. Sontakke SD, Reddy AP, Umapathy G, Shivaji S. Anesthesia induced by administration of xylazine hydrochloride alone or in combination with ketamine hydrochloride and reversal by administration of yohimbine hydrochloride in captive Axis deer (Axis axis). Am J Vet Res. 2007;68(1):20-4. Doi: 10.2460/ajvr.68.1.20.

18. Hall LW, Clarke KW, Trim CM. Anaesthesia of sheep, goats, and other herbivores. In: Clarke KW, Trim CM, Hall LW, editors. Veterinary anaesthesia. 11st ed. London: Saunders; 2013. 345-83 p. Doi: 10.1016/B978-0-7020-2793-2.00013-X.

19. Haulton S, Porter W, Rudolph B. Evaluating 4 methods to capture white-tailed deer. Wildl Soc Bull. 2001;29(1):255-64. [available here]

20. Caulkett N, Haigh J. Anesthesia of north american deer. In: Heard D, editor. Zoological restraint and anesthesia. New York: International Veterinary Information Service; 2004.1-72 p. [available here]

21. Siegal-Willott J, Citino SB, Wade S, Elder L, Hayek AC, Lance WR. Butorphanol, azaperone, and medetomidine anesthesia in free-ranging white-tailed deer (Odocoileus Virginianus) using radiotransmitter darts. J Wildl Dis. 2009;45(2):468-80. Doi: 10.7589/0090-3558-45.2.468.

22. Miller BF, Osborn DA, Lance WR, Howze MB, Warren RJ, Miller K V. Butorphanol-azaperone-medetomidine for immobilization of captive white-tailed deer. J Wildl. 2009;45(2):457-67. Doi: 10.7589/0090-3558-45.2.457.

23. Fitri WN, Wahid H, Rosnina Y, Jesse FFA, Aimi-Sarah ZA, MohdAzmi ML. Semen characteristics, extension, and cryopreservation of Rusa deer (Rusa timorensis). Vet World. 2017;10(7):779-85. Doi: 10.14202/vetworld.2017.779-785.

24. Mukaka MM. Statistics corner: A guide to appropriate use of correlation coefficient in medical research. Malawi Med J. 2012;24(3):69-71.

25. Walsh V, Wilson P. Sedation and chemical restraint of deer. N Z Vet J. 2011;50(6):228-36. Doi: 10.1016/j.cmpb.2016.01.020.

26. Kirschner SM, Rodenkirch R. Assessment of butorphanol-azaperonemedetomidine combination as anesthesia for semen collection and evaluation of semen quality in white-tailed deer (Odocoileus virginianus). Anim Reprod Sci. 2017:1-8. Doi: 10.1016/i.anireprosci.2017.07.016.

27. Powell D, Calle P. Anesthesia of male axis deer (Axis axis): Evaluation of thiafentanil, medetomidine, and ketamine versus medetomidine and ketamine. J Zoo Wildl Med. 2007;37(4):513-7. Doi: 10.1638/06-027.1.

28. Mentaberre G, López-olvera JR, Casas-díaz E, Bach-raich E, Marco I, Lavín S. Use of haloperidol and azaperone for stress control in roe deer (Capreolus capreolus) captured by means of drive-nets. Res Vet Sci. 2010;88(3):531-5. Doi: 10.1016/j.rvsc.2009.11.001.

29. Mcnulty E, Selariu AI, Anderson K, Hayes-klug J, Nalls A V, Powers JG. Aspects of the husbandry and management of captive cervids. Nat Publ Gr. 2016;45(4):140-2. Doi: 10.1038/laban.972.

30. Masters NJ, Flach E. Tragulidae, Moschidae, and Cervidae. $8^{\text {th }}$ ed. London: Elsevier Inc.; 2014. 611-625 p. Doi: 10.1016/B978-1-45577397-8.00062-1.

31. Johnson SK, Jones RD. A breeding stochastic model to compare system costs for synchronization of estrus and artificial insemination to natural. Prof Anim Sci. 2008;24(6):588-95. Doi: 10.15232/S10807446(15)30909-8.

32. Asher GW, Berg DK, Evans G. Storage of semen and artificial insemination in deer. Anim Reprod Sci. 2000;62(1-3):195-211. Doi: 10.1016/S0378-4320(00)00159-7.
33. Pintus E, Ros JL. Assisted reproductive technologies in deer. Sci Agric Bohem. 2014;45(2):136-46. Doi: 10.7160/sab.2014.450210.

34. Ramaswamy P, Babl FE, Deasy C, Sharwood LN. Pediatric procedural sedation with ketamine: Time to discharge after intramuscular versus intravenous administration. Clin Pract. 2008;16(2):101-7. Doi: 10.1111/j.1553-2712.2008.00311.x.

35. Mion G, Villevieille T. Ketamine pharmacology: An update (pharmacodynamics and molecular aspects, recent findings). CNS Neurosci Ther. 2013;19:370-80. Doi: 10.1111/cns.12099.

36. Ahmed AF, Al-Sobayil FA, Al-Rauji Y. An Evaluation of acepromazine/ketamine for immobilization of white-tailed deer (Odocoileus virginianus). Res J Vet Sci. 2010;3(2):118-26. Doi: 10.3923/rjvs.2009.1.9.

37. Li L, Vlisides PE. Ketamine: 50 Years of modulating the mind. Front Hum Neurosci. 2016;10:1-15. Doi: 10.3389/fnhum.2016.00612.

38. Knych H, Steffey E, Deuel J, Shepard R, Stanley S. Pharmacokinetics of yohimbine following intravenous administration to horses. J Vet Pharmacol Ther. 2011;34(1):58-63. Doi: 10.1111/j.13652885.2010.01194.x.

39. Allan MR. The use of ketamine-xylazine and ketamine-medetomidine with and without their antagonists yohimbine and atipamezole hydrochloride to immobilize Raccoons (Procyon lotor) in Ontario, Canada. Can Field-Naturalist. 2015;129(1):84-9. Doi: 10.22621/cfn.v129i1.1672.

40. Jin JF, Zhu LL, Chen M, Xu HM, Wang HF, Feng XQ. The optimal choice of medication administration route regarding intravenous, intramuscular, and subcutaneous injection. Patient Prefer Adherence. 2015;9:923-42. Doi: 10.2147/PPA.S87271.

41. Kurdi M, Theerth K, Deva R. Ketamine: Current applications in anesthesia, pain, and critical care. Anesth Essays Res. 2014;8(3):283. Doi: 10.4103/0259-1162.143110.

42. Center for Food and Nutrition Policy. Livestock Characterization. Virginia Tech-Alexandria; 2002. [available here]

43. Mahre M, Wahid H, Rosnina Y, Jesse F. Assessment of temperament in Rusa timorensis and its relationship to stress. Am Soc Anim Sci. 2015:1276-83.

44. Lamb G, Mercadante V. Synchronization and artificial insemination strategies in beef cattle estrus synchronization artificial insemination beef cattle economics. Vet Clin NA Food Anim Pract. 2016;1-13. Doi: 10.1016/j.cvfa.2016.01.006.

45. Turbill C, Ruf T, Mang T, Arnold W. Regulation of heart rate and rumen temperature in red deer: Effects of season and food intake. J Exp Biol. 2011;214:963-70. Doi: 10.1242/jeb.052282.

46. Abrahamsen E. Current veterinary therapy: Food animal practice. $5^{\text {th }}$ ed. Missouri: Saunders; 2008. 552-558 p.

47. Stewart JL, Shipley CF, Ellerbrock RE, Schmidt L, Lima FS, Canisso IF. Physiological variations in reproductive and metabolic features of white-tailed deer (Odocoileus virginianus) bucks throughout the rutting season. Theriogenol. 2018;114:308-16. Doi: 10.1016/j.theriogenology.2018.04.015.

48. Pisu MC, Ponzio P, Rovella C, Baravalle M, Veronesi MC. Usefulness of an injectable anaesthetic protocol for semen collection through urethral catheterisation in domestic cats. J Feline Med Surg. 2016;1-4. Doi: $\underline{10.1177 / 1098612 X 16679589}$.

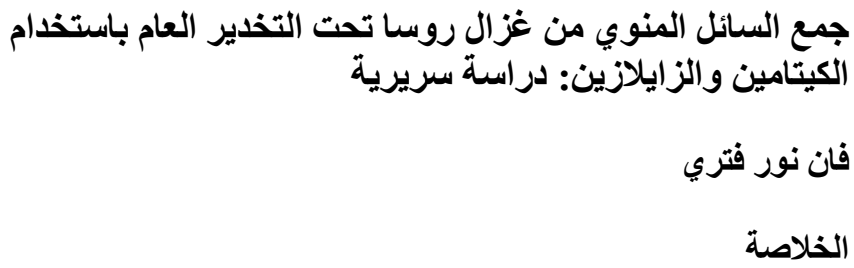

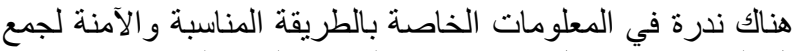
السائل المنوي من غزال روسا. يوفر التخدير العام بالكيتامين-زيلازين عن طريق الحقن بالوريد أو العضل على على حد سو اء معلومات قيمة لإجر العراء 
$\varepsilon, \cdot 1 \pm r q, \cdot V$ ( $1, \cdot r \pm 11, V r$ (1, $\varepsilon \varepsilon \pm 11, T V, 1, \varepsilon V_{ \pm} \mid \Lambda, T V$

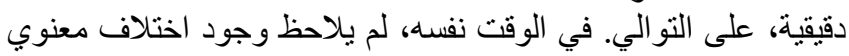

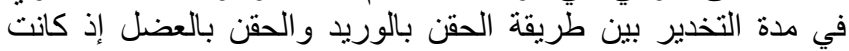

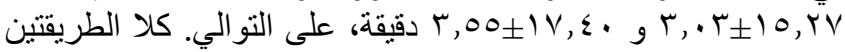

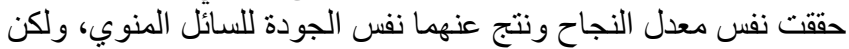

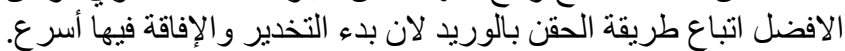

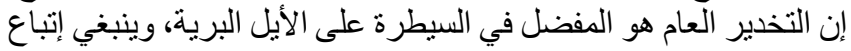
طريقة الحقن بالوريد لجمع السائل المنوي من غز لالان الأن روسا.
هذه العملية. نم اختيار خمسة من من غز ال روسا البالغة لهذه الدراسة،

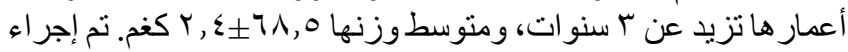

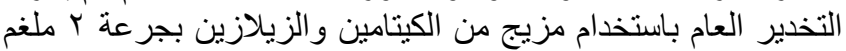

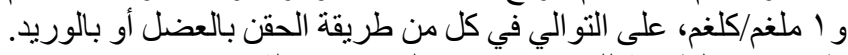

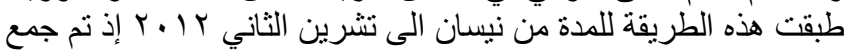

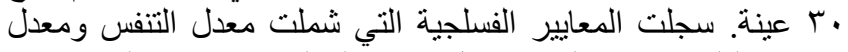

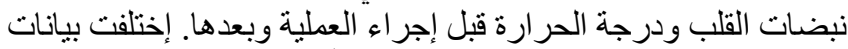

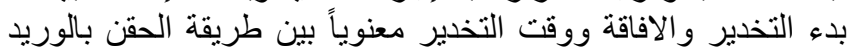

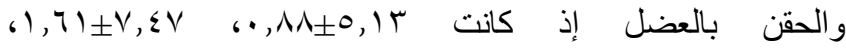

